\title{
Crónica
}

\section{Seminario Desarrollo Humano}

\author{
Marcela Maldonado \\ Vicaria de Pastoral Social Caritas \\ Arzobispado de Santiago \\ mmaldonado@iglesiadesantiago.cl
}

El pasado martes 21 de agosto 2019 se realizó el Seminario "Desarrollo humano, políticas públicas y comunidades", convocado por el Programa de Teología, Ética y Economía UC y organizado por la Escuela de Trabajo Social UC, la Vicaría de Pastoral Social Caritas, la Fundación Trabajo para un Hermano y Flacso.

El seminario comenzó con una conferencia de Severine Deneulin, doctora en estudios de desarrollo de la Universidad de Oxford. En su exposición, la académica se refirió al pensamiento de Amartya Sen y su contribución al desarrollo o progreso de los pueblos. En su intervención destacó la perspectiva de Sen sobre la libertad de cada persona y los efectos de los mercados en la vida de las mismas.

Severine Deneulin expresó que el pensamiento de Sen podría ayudar, desde las comunidades, a pensar el desarrollo humano.

Su contribución está en analizar las instituciones e identificar las definiciones de bienestar de las personas. Además, aportar a que las comunidades puedan identificar los problemas más grandes, Sen podría ayudar a identificar los procesos que afectan su vida.

Luego de la conferencia, Rodrigo Márquez, de Flacso, dio a conocer la sistematización de los aportes que dirigentes sociales reflexionaron en torno al concepto de desarrollo humano, en el conversatorio realizado el 2 de agosto en el Santuario del Padre Hurtado. Sobre ello, explicó que las personas, desde su experiencia, definen el desarrollo humano

con ir más allá de lo económico, lograr equilibrio entre lo económico y lo humano, que cada persona pueda lograr sus metas, el respeto a los seres vivos y al medioambiente, aceptar al otro, la empatía, dignidad e inclusión. 
La sistematización también arrojó otras conclusiones en torno a los logros y desafíos que las comunidades ven en relación al desarrollo humano en Chile. En este sentido, el representante de Flacso dijo que las personas ven avances en aspectos de la vida, tales como la tecnología, la igualdad de género, respeto por diversidad de formas de vida, mayor acceso a la información. Respecto a los desafíos, se destaca reducir la desigualdad, la calidad de oportunidades y el tener acceso a decisiones colectivas.

En el seminario, un panel de expertos se refirió al tema "desarrollo humano, políticas públicas y comunidades".

Desde el ámbito de la psicología, el académico de la Universidad Católica, Roberto González, señaló que cada vez que los seres humanos nos vemos enfrentados a tensiones ligadas al crecimiento, a la falta de recursos cuando priman nuestras necesidades por sobre las colectivas, normalmente entramos a una tensión que no necesariamente conduce al desarrollo. Nos desarrollamos cuando la tensión nos hace pensar acerca de las necesidades propias legítimas, pero en sintonía con las de los otros.

Las normas pueden cambiar, no son estables, por tanto, el desarrollo es un elemento que habla de la dinámica del cambio social, eso supone que tenemos que entender desde la perspectiva de las personas.

En tanto, desde las empresas B, Josefa Monge expresó que en las empresas B, queremos interpelar desde lo positivo, desde el amor, desde el cariño a hacer un cambio en la manera de hacer negocios, en cómo vemos la empresa y queremos usar la fuerza del mercado para solucionar problemas sociales y medioambientales y es imposible hacerlo sin la comunidad. 